\title{
More Structural Analogies Between Pronouns and Tenses
}

\author{
Angelika Kratzer \\ University of Massachusetts at Amherst
}

\section{The plot}

In the early seventies, Barbara Partee suggested that tenses in natural languages might not be operators, but pronouns. Like pronouns, they have indexical, anaphoric, and bound variable uses. In this short presentation, I will discuss one more parallel between tenses and pronouns. Sometimes, tense features are not interpreted at all, a phenomenon traditionally called 'sequence of tense'. Here are some illustrations:

(1) John decided a week ago that in ten days he would say to his mother that they were having their last meal together.

(Abusch 1988)

(2) John said he would buy a fish that was still alive.

(Ogihara 1989).

(3) Mary predicted that she would know that she was pregnant the minute she got pregnant.

In sentences (1) to (3), the underlined tenses are not necessarily interpreted as past tenses. All three sentences have readings where those tenses seem to merely agree with a higher past tense without making any semantic contribution of their own. Surprisingly, indexical pronouns can behave in a similar way. Sometimes, their features are nor interpreted. Here is an example that Irene Heim has been using in class lectures:

(4) Only I got a question that I understood.

(4) has two readings. On one reading (the strict reading), the sentence describes a situation where nobody else got a question that I understood. On this reading, the second occurrence of $I$ has its usual indexical interpretation: it picks out the speaker of the utterance. On the second reading (the sloppy reading), (4) says that apart from me, no individual (or group of individuals) had the property of being an $x$ such that $\mathrm{x}$ got a question $\mathrm{x}$ understood. This is the reading we are interested in: the person and number features of the second $I$ are not interpreted, and the pronoun has a bound variable interpretation.

In what follows, I will first explore why pronominal features that are in principle interpretable are not always interpreted. And I will then suggest that the explanation given to the pronominal case carries over to the temporal cases. Possible 'loss of interpretable features', then, is just one more property that is shared by pronouns and tenses.

There is a major obstacle to the project I have just outlined, however. There are some cases where tenses don't seem to be interpreted as pronouns. Here is an example:

(5) He will marry a woman who went to Harvard. 
It is hard to see how we could get away with a pronominal interpretation of the past tense in (5). If pronominal, that tense should necessarily refer to a time interval that precedes the utterance time, which it does not. Examples like these have motivated proposals that assume that tenses denote operators. In (5), the modal will, shifts the current evaluation time to some point in the future, and the embedded past tense takes us back in time from there. We can't seem to do without operators here. But who says that it has to be tenses that host that kind of operator? It has been recognized for quite some time, for example, that modals may be associated with future 'tense'. I will show below that aspectual markers can be the hosts of operators that take us back in time. More specifically, I will argue that perfect aspect might get confused with past tense. When you think that tenses denote operators, you are not really talking about tenses in a technical sense. Tense, aspect and modality interact in intimate ways so as to fool us about their individual contribution to the temporal properties of sentences.

\section{Indexical Pronouns that are Bound Variables}

Look again at Heim's example (4):

$$
\text { Only I got a question that I understood. }
$$

We have seen that the second occurrence of $I$ in (4) can have an indexical or a bound variable interpretation, and this is the point Heim has been making over the years. I has always seemed the prime example of an indexical pronoun, but here it lets us down. How can we deal with such a pronoun? It would be natural to assume ambiguity. There could be an indexical $I$, and this is the $I$ we have always known. And there could be a bound variable $I$ that is just that: a mere bound variable. Indexical $I$ is assigned the speaker of the utterance context as its denotation. Bound variable $I$ needs an index, and receives its denotation from the variable assignment. The variable assignment only sees the index, and doesn't care about the lexical item the index is attached to. Consequently, the features of the pronoun are ignored. For any context $\mathrm{c}$ and variable assignment $\mathrm{g}$ we have:
$[[I]] \mathrm{g}, \mathrm{c}=\operatorname{speaker}(\mathrm{c})$.
$\left[\left[I_{n}\right]\right] \mathrm{g}, \mathrm{c}=\mathrm{g}(\mathrm{n})$.
Indexical Interpretation
Variable Interpretation

The proposal I sketched above seems obvious enough, yet it can't stand as is. So far, there is nothing in the theory to prevent the index on $I$ from staying free. It is common to have third person pronouns whose index is not bound. Those pronouns receive their value from a variable assignment. If we think of utterance contexts as imposing constraints on admissible variable assignments, a pronoun with a free index is a pronoun whose value is contextually provided. But if $I$ is a variable, it can't be a free variable. If it has a lexical index, that index has to be bound. Where should this requirement come from? Should the syntax of Logical Form recognize a major difference between indexical and non-indexical pronouns? ${ }^{1}$ And should there be a stipulation barring indexical pronouns with indices that are not bound? What started out as a routine account of Heim's observation begins to look odd. It would be odd to stipulate that indexical pronouns can have indices as long as they don't stay free. In addition, there would have to be other, more substantial, stipulations. Surprisingly, bound variable indexicals obey locality constraints not shared with third person bound variable pronouns. Here are some illustrations: 
Ambiguous: strict and sloppy reading

(6) Only I got a question that I thought I could answer.

(7) Only I considered the question whether I should leave before I got bored.

Unambiguous: strict reading only

(8) Only I got a question that you thought I could answer.

(9) Only I think that Mary won't come if I invite her.

Ambiguous: non-indexical pronouns

(10) Only this man got a question that you thought he could answer.

(11) Only this man thinks that Mary won't come if he invites her.

What seemed like a straightforward implementation of Heim's proposal, then, is only viable if an odd bundle of conditions is attached. In the following section, I will propose a new way of looking at the typology of pronouns that accommodates Heim's example without special stipulations and can easily be extended to the temporal case.

\section{Zero Pronouns That Can be Pronounced}

The sloppy reading of Heim's example conf ronted us with a pronoun that looks just like a first person pronoun, but can semantically behave as if it didn't have any agreement features ( $\phi$-features) at all. How can this happen? It seems plausible to assume that interpretable features can't ever be gotten rid of in the process of deriving Logical Form (LF) representations. Since $\phi$-features are interpretable, and we find pronouns without $\phi$-features at LF, I conclude that there must be pronouns that start their syntactic life without $\phi$-features. I will refer to such pronouns as 'zero pronouns', and symbolize them as ' $\varnothing$ '. Zero pronouns in this sense should not be confused with unpronounced pronouns. Zero pronouns may acquire a pronunciation from a suitable antecedent at PF (Phonetic Form).

The source of the sloppy reading of sentence (4) would now be a representation like (4'):

(4') [Only I $]_{1}$ got a question that $\varnothing_{1}$ understood.

Presupposing the inverted $\mathrm{Y}$-model of much recent syntactic research (e.g. Chomsky 1995), the life of a first person pronoun that is interpreted as a bound variable would look as follows: 


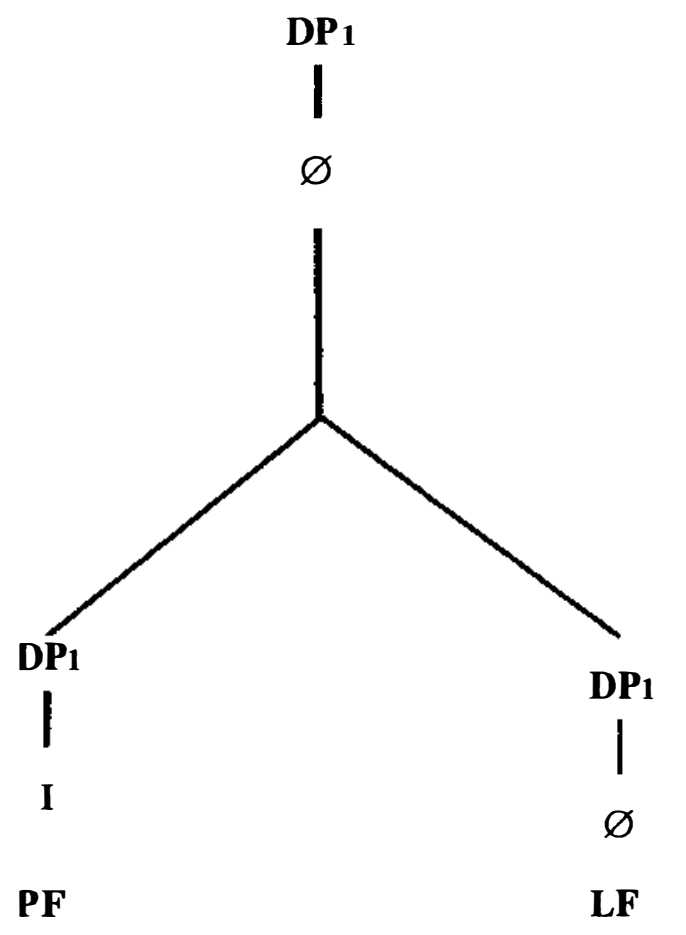

Figure 1

Assuming the existence of zero pronouns that can be pronounced has many interesting consequences, and affects the very way we have to think about pronouns. Since this presentation has to be short, and should ultimately lead to a discussion of tenses, I will not be able to investigate the properties of zero pronouns in great detail. I will, however, pursue the topic to a point where the empirical merits of the proposal outlined above can be appreciated.

After the admission of zero pronouns, the 'input' or 'underlying' inventory of English pronouns looks as follows 2 :

The inventory of English 'input' pronouns

Indexicals:

Variables:

Zero pronouns:

$$
\begin{aligned}
& I, \text { you, we } \\
& \text { he }_{n}, \text { she }_{n}, \text { it }_{n}, \text { they } \\
& \varnothing_{n}
\end{aligned}
$$

\section{The interpretation of (selected) English pronouns}

$[[I]] \mathrm{g}, \mathrm{c}=$ speaker $(\mathrm{c})$

[[he $n]] \mathrm{g}, \mathrm{c}$ is only defined if $\mathrm{g}(\mathrm{n})$ is a singular male individual. If defined, [[he $n]] \mathrm{g}, \mathrm{c}$ $=\mathrm{g}(\mathrm{n})$.

$\left[\left[\varnothing_{n}\right]\right]^{\mathrm{g}, \mathrm{c}}=\mathrm{g}(\mathrm{n})$.

Having zero pronouns lets us treat pronouns in the semantics as we always have. Indexical pronouns cannot have lexical indices since they cannot be interpreted by the variable assignment 3 . Third person pronouns and zero pronouns must have lexical indices since they receive their denotation from the variable assignment. The $\phi$-features of third person pronouns contribute a presupposition. Since zero pronouns do not have $\phi$-f eatures, they lack presuppositions. 
Zero pronouns must have an antecedent. And as sentences (8) and (9) show, there are locality constraints for the anaphoric relationship that zero pronouns must enter. The major empirical challenge we are facing with zero pronouns is to derive the properties of that relationship. Look at the unavailable sloppy readings of sentences (8) and (9), which contrast with the available sloppy readings for (6) and (7):

(8') * [Only I $]_{1}$ got a question that you thought $\varnothing_{1}$ could answer.

(9') * [Only I $]_{1}$ think that Mary won't come if $\varnothing_{1}$ invite her.

(6') [Only I $]_{1}$ got a question that $\varnothing_{1}$ thought $\varnothing_{1}$ could answer.

(7') [Only I $]_{1}$ considered the question whether $\varnothing_{1}$ should leave before $\varnothing_{1}$ got bored.

Extending the data base so as to include objects, we may add:

(12) They only asked ME whether I could answer the question.

(13) Only I think that Mary will invite me.

(14) They only asked ME whether you thought I could answer the question.

(15) Only I think that Mary won't come if you invite me.

(12) and (13) have sloppy readings, (14) and (15) don't:

(12') They only asked $\mathrm{ME}_{1}$ whether $\varnothing_{1}$ could answer the question.

(13') [Only I $]_{1}$ think that Mary will invite $\varnothing_{1}$.

(14') * They only asked $\mathrm{ME}_{1}$ whether you thought $\varnothing_{1}$ could answer the question.

$(15)^{\prime} *[\text { Only I }]_{1}$ think that Mary won't come if you invite $\varnothing_{1}$.

The generalization emerging at this point is roughly that the relation between a zero pronoun and its antecedent cannot be interrupted by an intervening clause. Is this a generalization that we know from other domains? As a matter of fact, we do: controlled PRO is submitted to this constraint, too. It needs an antecedent, and the anaphoric relation between it and its antecedent (the 'control relation') can't be interrupted by an intervening clause. Controlled PRO, then, is likely to be a special case of a zero pronoun. If this turns out to be correct, then what has traditionally been called 'PRO' would be merely the PF realization of $\varnothing$ in the subject position of a non-finite clause (in English), hardly a theoretically exciting creature.

In the subject positions of finite clauses, zero pronouns are pronounced in English, acquiring the necessary features from their antecedent. Cases of pronounced subject pronouns that have to be 'controlled' have been reported in Hashemipour 1988 for Persian, in Yang 1985 for Korean, Japanese, and Chinese, and in Borer 1989 for Korean, Italian, and Saramaccan. Saxon 1984 has cases of controlled unpronounced subjects of finite clauses in Dogrib, and Borer 1989 presents similar evidence from Hebrew and Chinese. Since all of those pronouns have to be controlled, they would have to start out as zero pronouns on the present account.

We have just seen that zero pronouns may or may not end up unpronounced. The exact principles guiding the pronunciation of zero pronouns do 
not have to concern us here, but we may expect economy principles of the kind proposed in Cardinaletti and Starke $(1994,1995)$ to play a role 4 . Zero pronouns seem to surface as the 'weakest' pronouns permissible in the position they find themselves in. If unpronounced pronouns are the 'weakest' (PF) pronouns in a given language, a zero pronoun that occurs in a position where unpronounced pronouns are permitted should have to surface as unpronounced. This expectation is confirmed by the following example from Spanish5:

(16) Sólo yo tenía una pregunta que yo entendía (strict reading only). only I got a question that I understood

(17) Sólo yo tenía una pregunta que entendía (strict and sloppy reading). only I got a question that pro understood

Since Spanish allows unpronounced pronouns as subjects of finite clauses, (16) lacks a sloppy reading. The pronoun yo cannot spell out a zero pronoun. Note that (17) has both a sloppy and a strict reading. This means that not all occurrences of unpronounced pronouns originate as zero pronouns. Pronouns that start out with a full set of agreement features may end up unpronounced as well.

Sentence (13) shows that zero pronouns can also occur in object position, and there is nothing I have said so far that would bar them from there. Are there other sightings of obligatorily controlled object pronouns in the literature? Unfortunately, the extant discussions of pronouns mostly look at their PF realizations, and don't discuss examples that would reveal a hidden zero source. Most relevant to the current proposal is the work of Hendrick (Hendrick 1983, 1988), who argues that relative pronouns, whether pronounced or not, have the properties of $\mathrm{PRO}$, including control properties. If this is so, relative pronouns would be instances of zero pronouns that can be pronounced and may originate in case marked object positions of various kinds.

Where do the locality constraints for zero pronouns come from? In the spirit of Chomsky 1995, we would want to avoid special locality constraints for special pronouns. I think a promising answer to the locality question emerges if we combine an important insight about switch reference systems by Daniel Finer (Finer 1984,1985 ) with recent views on verbal agreement. Typical switch reference sentences can be schematically represented as follows (Finer 1985):
a. Before he left-SS, he $_{\mathrm{i}}$ visited Tucson.
b. Before he $\mathrm{i}_{\mathrm{i}}$ left-DS, he $\mathrm{j}_{\mathrm{j}}$ visited Tucson.
c. ${ }^{*}$ Before he $\mathrm{e}_{\mathrm{i}}$ left-SS, he $\mathrm{j}_{\mathrm{j}}$ visited Tucson.
d. ${ }^{*}$ Before he $_{\mathrm{i}}$ left-DS, he $\mathrm{i}_{\mathrm{i}}$ visited Tucson.

In (18), 'SS' stands for a 'Same Subject' marker, 'DS' stands for a 'Different Subject' marker, and $\mathrm{i} \neq \mathrm{j}$. Finer explained switch reference phenomena in a number of languages by assuming that the switch reference markers typically found in subordinate clauses are elements that are subject to the binding theory. SSmarkers are anaphors that must be coreferential with the subject agreement marker of the next higher clause. It follows that the embedded and the higher subject are coreferent. DS-markers are pronouns and must be disjoint in ref erence from the subject agreement marker in the next higher clause. Consequently, the embedded subject and the higher subject are disjoint in reference. The novel feature of Finer's account is that the same-subject or different-subject relation is determined through a strictly local relation between two functional heads. Borer 1989 and Hale 1992 
pursue related proposals for the control relation, and this establishes the link to zero pronouns.

We are now prepared to deduce the locality constraints for zero pronouns. Following Finer, Borer, and Hale, not necessarily local anaphoric relations between noun phrases will be reduced to strictly local relations between functional heads. In our case, the functional heads are agreement heads. Following Chomsky 1995, I am assuming that there are subject and object agreement heads as part of an extended verbal projection. Departing from Chomsky's recent work, I am assuming that verbs move through the hierarchy of inflectional heads to pick up inflectional features rather than merely checking features of fully inflected verbs. For reasons of space, I will only consider subjects and direct objects. Here is an overview of the main facts to be accounted for:

a. An embedded zero subject may be anaphoric to a matrix subject.

b. An embedded zero subject may be anaphoric to a matrix object.

c. An embedded zero object may be anaphoric to a matrix subject.

d. An embedded zero object may be anaphoric to a matrix object.

To have a concrete example, look at the following sentence:

$[\text { Only I }]_{1}$ told you that I am tired.

(20) has a sloppy reading, and in this case, the second occurrence of $I$ starts out as a zero pronoun. On this reading, (20) is an instantiation of 19(a): The antecedent of the embedded zero subject is the matrix subject rather than the more local matrix object. How can this be? Following the model of Finer, we are looking for an explanation that relies on anaphoric relations between agreement heads, rather than on anaphoric relations between the participating noun phrases themselves. Our first task, then, is to establish a connection between zero pronouns and anaphoric agreement heads. What is it that forces an agreement head whose specifier position hosts a zero pronoun to be anaphoric? Here is a possibility: Suppose an agreement head and the noun phrase in its specifier position must agree when the agreement phrase is built. When an agreement phrase that has a zero pronoun in its specifier position is constructed, then, the agreement head can't have $\phi$-f eatures, but must be a zero head itself. Being zero, it must find a local antecedent of the same kind as the derivation proceeds, merging the initial agreement phrase into a larger structure.

Let us now look at the line-up of functional heads in (20):

$$
\mathrm{AGR}_{\mathrm{s}} \ldots . . \mathrm{AGR}_{\mathrm{o}} \ldots . . \mathrm{V} \ldots \mathrm{C} \ldots . . \mathrm{AGR}_{\mathrm{s}} \ldots . \mathrm{V} \ldots
$$

As depicted in (20'), the matrix object agreement marker is closer to the embedded subject agreement marker than the matrix subject agreement marker. But this situation will change when the higher verb starts moving. After the matrix.V has adjoined to the matrix $\mathrm{AGR}_{\mathrm{O}}, \mathrm{V}+\mathrm{AGR}_{\mathrm{O}}+\ldots$... (whatever intermediate functional heads there may be) will adjoin to $A_{G R}$, and at this point, the matrix $A_{G R}$ and $\mathrm{AGR}_{\mathrm{O}}$ will be equidistant 6 from the embedded AGRs. Consequently, the embedded $\mathrm{AGR}_{\mathrm{s}}$ can take the matrix $\mathrm{AGR}_{\mathrm{s}}$ as an antecedent without violating locality. The type of explanation I just gave assumes a version of Baker's Government Transparency Corollary (Baker 1988), which is a principle that extends the locality domain of a head $X$ to that of a head $Y$ if $Y$ adjoins to $X$. In our example, the matrix $A_{G R}$ becomes a local antecedent for the embedded $A_{G} R_{s}$ af ter the matrix $A_{G R}$ adjoins to it. This completes the explanation for 19(a). 
As for the remaining cases under (19), 19(b) needs no explanation, and this leaves 19(c) and (d). In 19(c) and (d), the embedded subject initially interrupts the relationship between the embedded object and any matrix noun phrase, but head movement of the embedded verb will eliminate this barrier as before.

Note that a zero pronoun in object position can also be anaphoric to the subject of its own clause, as the following sentence, which only has a sloppy reading, shows:

$$
\text { Only I pitied myself. }
$$

An anaphoric relationship between heads that end up to be part of the same verbal inflection affects the spell-out of the verbal inflection or the participating noun phrases in special ways, a point amply demonstrated in Reinhart and Reuland 1993.

If zero pronouns do not directly enter into anaphoric relationships with suitable antecedents, but need the mediation of their agreement head, we predict that zero pronouns should not be able to occur in conjoined structures, and this prediction is borne out. (22) only has a strict reading:

Only I got a question that you and I understood.

We now understand why the locality constraints for zero pronouns are the way they are. The anaphoric relationship between a zero pronoun and its antecedent can be interrupted by superficially closer suitable antecedents, as long as these barriers can be eliminated through movement on the way towards PF. Since head movement of the verb can go no further than the closest complementizer, intervening sentences interrupt the relationship between a zero pronoun and its antecedent, unless closeness can be established in some other way. Anaphoric relationships across an intervening sentence may become more easily available, for example, if the most embedded sentence is deaccented, as in (23), where repetition of answer contributes to the deaccenting of the embedded clause 7 :

Only I answered a question that you didn't think I could answer.

For (23), a sloppy reading seems more easily available than for (8). I think phonological reduction may favor extraposition of the embedded sentence. It could then be attached high enough in the tree so as to eliminate the barrier effect of the intervening sentence. Once this possibility is controlled for, sloppy readings disappear, as in (24), where a negative polarity item blocks 'high' extraposition:

Only I answered a question that you didn't think I would ever be able to answer.

What is so special about indexical pronouns? Why is it that they make such wonderful subjects for experimentation? Why don't we get the same kind of effects with third person pronouns? The answer to these questions can be found in the semantics for pronouns given at the beginning of this section. Unlike indexical pronouns, third person pronouns have variable interpretations to begin with. They don't have to start out as zero pronouns to become variables that may produce sloppy readings. A possible zero origin may therefore easily go unnoticed. There is a slight, but still detectable difference between those third person pronouns that start out as zero pronouns and those that don't, however. Recall that zero pronouns don't have presuppositions, unlike third person pronouns with agreement features. We predict therefore that a free third person pronoun has presuppositions triggered 
by its agreement features, but these presuppositions may be missing when the pronoun is bound. In spite of the gender wars, there is still a difference between (25) and (26):

$\mathrm{He}_{1}$ left.

Who $_{1}$ thinks he ${ }_{1}$ is God?

For (25) to be acceptable, the utterance context has to provide a salient male individual. But the question operator in (26) does not necessarily range only over male individuals, at least for some speakers. Unlike the he in (25), the he in (26) can originate as a zero pronoun.

There is one remaining issue about the semantics of zero pronouns that I have to address. Sometimes, the presence of a zero pronoun has the effect that a sentence denotes a property, rather than a proposition. Here is an example of a reduced relative clause:

$$
\text { [......man } \operatorname{man}_{1}\left[\varnothing_{1} \text { attentive to his }{ }_{1}\right. \text { own needs..] }
$$

Following Heim and Kratzer 1998, (27) is interpreted as follows: the index on man cannot be a lexical index, since man doesn't have an assignment dependent denotation. Consequently, the index is a binder index ( $\lambda$-operator), and (27) is in fact parsed as (27'):

$$
\text { [.....man [ } 1\left[\varnothing_{1} \text { attentive to his }{ }_{1}\right. \text { own needs..] ] }
$$

The binder index 1 can now bind the embedded zero pronoun, and the constituent following man expresses a property, as it should.

Now look at a control case:

$$
I_{1} \text { promised you } \varnothing_{1} \text { to quit. }
$$

In this case, it is not obvious that the index on $I$ is in the right configuration to be parsed as a binder whose scope is just the embedded infinitive at LF. Moreover, the binding constraints for zero pronouns allow both $I$ and you as antecedents. In reality, however, only $I$ is a possible antecedent for $\varnothing_{1}$ in (28). That this is so, is due to lexical properties of promise. Suppose that lexical control properties are checked at LF. LF represenations would be illicit, for example, if in (28), you rather than $I$ was coindexed with the zero pronoun. Moreover, as part of the checking of lexical requirements, the embedded clause is prefixed with a binding index that matches that of the controller. The infinitival clause will now denote a property, and this is what the semantics of control verbs requires. The result is $\left(28^{\prime}\right)$ :

$$
\mathrm{I}_{1} \text { promised you } 1\left[\varnothing_{1}\right. \text { to quit]. }
$$

\section{Analogies Between Tenses and Pronouns}

Recent papers by Abusch, Ogihara, v.Stechow, and Stowell (Abusch 1997, Ogihara 1995, v. Stechow 1995, Stowell 1996), as well as the commentaries on Abusch by Heim and v. Stechow (Heim 1994, v. Stechow 1994), have contributed 
a great deal to our understanding of the difficult semantics of embedded tenses. Yet none of those papers has managed to get rid of all stipulations about tenses. Ogihara and $v$. Stechow have syntactic rules that delete tenses under certain conditions. Abusch relies on a mechanism that transmits temporal relations.Stowell stipulates that there are two pieces to tense morphology that have to be related in a particular way.

The goal of the remainder of this presentation is to show that it is possible to do away with special stipulations about tenses while preserving the essential insights of the earlier formal semantic work on the sequence of tense phenomenon. For reasons of space, I will have to rely heavily on the main results of the easily accessible articles by Abusch and Ogihara without reviewing them in detail. In particular, I will presuppose acquaintance with Abusch's and Ogihara's important observations about the availability of temporal de se and de re readings.

If tenses are special kinds of pronouns, we expect the repertoire of (input) tenses to have a similar structure as the repertoire of (input) pronouns. In particular, we should find a zero tense that behaves like a zero pronoun. Here is a concrete proposal:

The inventory of English (input) tenses

present [[present $]] \mathrm{g}, \mathrm{c}$ is only defined if $\mathrm{c}$ provides an interval $\mathrm{t}$ that includes $\mathrm{t}_{0}$ (the utterance time). If defined, then $[[$ present $]] \mathrm{g}, \mathrm{c}=\mathrm{t}$.

past

$[[$ past $]] \mathrm{g}, \mathrm{c}$ is only defined if $\mathrm{c}$ provides an interval $\mathrm{t}$ that precedes $\mathrm{t}_{0}$. If defined,then $[[$ past $]] \mathrm{g}, \mathrm{c}=\mathrm{t}$.

$\varnothing_{n} \quad\left[\left[\varnothing_{n}\right]\right]^{\mathrm{g}, \mathrm{c}}=\mathrm{g}(\mathrm{n})$

On this proposal, English has two indexical tenses, and a zero tense. Like zero pronouns, zero tenses are lexically indexed variables that have no presuppositions and must be bound by a local antecedent. Since there is only one tense per clause, a zero tense must be anaphoric to the tense in the next higher clause, since this will always be the closest possible antecedent. Being a naphors, zero tenses can pick up features from their antecedents that make it possible for them to be pronounced in finite clauses. I think no more (hence nothing special) has to be said about the semantics or pronunciation of tenses. Whatever is special about tenses, is part of their lexical information. Tenses and pronouns belong to different syntactic categories, and this determines the choice of possible local antecedents for zero tenses. Tenses are functional heads, and this means that they have to enter anaphoric relationships directly, without mediation of other elements. And there are differences in the type of denotation. All tenses denote time intervals, but few pronouns do.

\section{Temporal $\mathrm{De} S \mathrm{Se}$}

The temporal de se can best be illustrated with sentences of the following kind (see e.g. v. Stechow 1982):

John thinks that it is 10 o'clock .

If the tense in (29) was indexical, and (29) was uttered at 11 o'clock, for example, then (29) would say that John thinks that 11 o'clock is 10 o'clock. That's not the prominent reading of that sentence, however. On its most 
natural reading, (29) says that John 'temporally self-locates himself' at 10 o'clock. For all he believes, the time he is at is 10 o'clock. Even in less dramatic cases, the tense of sentential complements embedded under attitude verbs is interpreted de se. Look at (30):

$$
\text { John thinks that he has a headache. }
$$

(30) says that John self-locates himself at a time where he has a headache. It seems, then, that embedded tenses are generally interpreted de se. If this is correct, sentential complements embedded under attitude verbs should express properties of times. They can do this if the highest tense of attitude complements is bound by a local $\lambda$-operator. This is what v. Stechow 1995 calls 'Abusch's Constraint'. Within the present framework, we would formulate Abusch's constraint as follows:

\section{Abusch's Constraint}

In attitude contexts, the highest tense is controlled by the matrix tense.

As expected, Abusch's Constraint is derivable from lexical properties of attitude verbs. The information that attitude verbs need complements that denote properties of times is part of the semantics of attitude verbs. That is, attitude verbs are of semantic type $<<\mathrm{i},<\mathrm{s}, \mathrm{D}\rangle,<\mathrm{e},<\mathrm{s}, \mathrm{t}>>>8$. They map properties of times into properties of individuals. The question is how we can get the complements embedded under attitude verbs to denote properties of times. Let us assume (for convenience only) that the highest interpretable node of a finite sentential complement is a TP with the following structure:

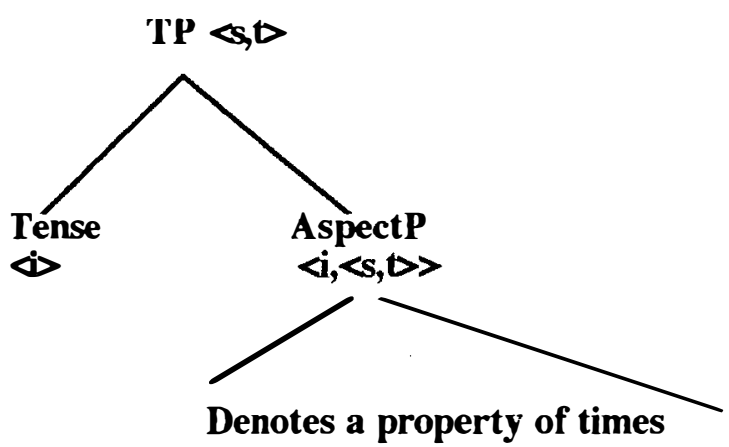

Figure 2

In the structure of figure 2, the tense node appears as sister of an Aspect Phrase. Aspect Phrases denote properties of times, as we will see below. Tense itself denotes a time, hence the whole TP denotes a proposition, unless the tense is zero, and a binder index is inserted at LF. In that case, the TP denotes a property of times. Now look again at (29). If the embedded tense in (29) is present, the embedded complement will denote a proposition, which it should not. If the embedded tense is a zero tense, however, insertion of a binder index at LF will yield the property we want. Here is a sketch of the semantic interpretation procedure: 
a. [TP present ${ }_{1}\left[\mathrm{John}\right.$ think that [TP $\varnothing_{1}$ [it be 10 o'clock] ] ] ].

b. [TP present $1\left[\mathrm{t}_{1}\right.$ [John think that $1\left[_{\mathrm{TP}} \varnothing_{1}[\right.$ it be 10 o'clock] ] ] ] ].

c. For all of John's doxastic alternatives $<w, \downarrow$ in $\mathrm{w}_{0}$ at $\mathrm{t}_{0} 9$ :

$[\lambda t . \lambda w$. it is ten o'clock at $t$ in $w](t)(w)=1$.

In step (b), the matrix tense is raised, leaving a trace. This raising is forced, since being an indexical, the present tense doesn't have a lexical index. The only way for the index on the present tense to be interpreted, then, is as a binder index, and this necessitates raising (see Heim and Kratzer 1998). Lexical requirements of the attitude verb are responsible for insertion of the lower binder index that can bind $\varnothing_{1}$. When that binder index is inserted, it 'breaks' the binding relationship between embedded and matrix tense. It is now the semantics of the attitude verb that connects the two tenses. At PF, however, the binding relationship between matrix and embedded tense is uninterrupted and determines the physical appearance of the downstairs tense. If the upstairs tense in (31) had been past, the downstairs tense would have been spelled out as past as well.

Example (32) has a relative clause in the scope of a past tense:
a. John bought a fish that was still alive
b. $\quad\left[\mathrm{TP}_{\mathrm{P}}\right.$ past $_{1}\left[\mathrm{John}\right.$ buy a fish that ${ }_{2}\left[\mathrm{TP} \varnothing_{1}\left[\mathrm{t}_{2}\right.\right.$ be still alive $\left.\left.]\right]\right]$.
c. [TP past $_{1}\left[\mathrm{John}\right.$ buy a fish that ${ }_{2}\left[\mathrm{TP}\right.$ past $_{1 / 3}\left[\mathrm{t}_{2}\right.$ be still alive] ] ] ].

In (32), w e have the option of either using a zero tense or a past tense in the relative clause. If we use a past tense, we may or may not coindex it with the upstairs tense. But note that if we use the zero tense, no binder index is inserted. Whether we choose option (b) or (c), the downstairs tense is always spelled out as past. .

A more complicated example is (33):
a. John said he would buy a fish that was still alive.
b. $\quad \int_{\mathrm{TP}}$ past $_{1}\left[\mathrm{John}\right.$ say that $1\left[\varnothing_{1}\left[\right.\right.$ will $1\left[\varnothing_{1}\right.$ he buy a fish that ${ }_{2}$ $\left[{ }_{\mathrm{TP}} \varnothing_{1}\left[\mathrm{t}_{2}\right.\right.$ be still alive] ] ] ] ] ] ].
c. $\quad \mathrm{TTP}_{\mathrm{TP}}$ past $_{1}\left[\mathrm{John}\right.$ say that $1\left[\varnothing_{1}\left[\right.\right.$ will $1\left[\varnothing_{1}\right.$ he buy a fish that ${ }_{2}$ [TP past $_{1 / 3}\left[\mathrm{t}_{2}\right.$ be still alive] ] ] ] ] ] ].

In (33), say, and will semantically select properties of times, hence force the embedded tense to be a zero tense with a binder index. There are various options for the tense in the relative clause, including zero tense. As mentioned in the introduction, there is an interpretation of this kind of relative clause that we can't account for yet (see the discussion of sentence 5 above), but this defect will be remedied shortly. The important point is that the tense of a relative clause can be bound or free, unlike the tense of a sentential complement of an attitude verb, which has to be controlled. This difference follows from the present framework without stipulations. As for the pronunciation of (33), the sentential complement embedded under say is finite, hence its tense is pronounced. The clause embedded under will is non-finite, hence its tense is unpronounced. While being unpronounced, that tense is still an important link, since through a chain of local anaphoric 
relationships, it can transmit a past feature to a possible zero tense in the finite relative clause.

Finally look at the contrast between (34) and (35):

(34) a. John thought two days ago that you would be sick yesterday.

b. $\lambda t . \lambda w$. there is a time $t$ ' after $t$ such that $t$ ' is part of yesterday $\&$ you are sick at $t^{\prime}$ in $w$.

(35) a. *John thought two days ago that you were sick yesterday.

b. $\lambda t . \lambda w . t$ is part of yesterday $\&$ you are sick at $t$ in $w^{10}$.

What is the difference between (34) and (35)? Here is a rough sketch of what the present account has to say about these cases. The semantics of think requires a zero tense with a binder index for the embedded clause in both cases. (34) says that two days ago, John located himself at a time and world with the property 34(b), and this seems fine. (35) says that two days ago, John located himself at a time and world with property 35 (b). For (35) to be true, then, John would have to have been under the illusion that the day he located himself at two days ago was yesterday, and this is what makes the sentence odd as an out of the blue utterance.

\section{Temporal De Re}

Both Abusch and Ogihara have observed that in attitude contexts, a present tense that is embedded under a past tense receives a particular interpretation. For Abusch, such attitude ascriptions are dere about a present time, for Ogihara, they are dere about a present state. (36) is an example with a paraphrase à la Ogihara:

(36) a. The ultrasound picture indicated that Mary is pregnant.

b. The ultra sound picture indicated of a present state of Mary's that it is a pregnancy.

Here is an attempt to derive an appropriate interpretation for sentences like (36). In (36)., the embedded tense cannot be anaphoric to the higher tense, since there is a feature mismatch. It seems, then, that the embedded tense cannot be a zero tense. But if it is not a zero tense, it must be an indexical tense. Consequently, the embedded sentence denotes a proposition, hence is not a suitable argument for the attitude verb. (36), then, should be ungrammatical. Sentences like (36) are in fact ungrammatical or marginal for many speakers, including some of my linguist colleagues. But there are enough speakers who like them, and this has to be explained. Suppose we take seriously the idea that attitude and similar verbs may have a res argument and can be interpreted de re with respect to event(ualities), as argued in Kratzer 1998. Event(uality) res arguments can be overtly represented, as in the following examples:

(37) a. What she said about her present state was that it's a pregnancy.

b. What she told us about her present state was...

c. What she knew about her present state was...

d. What she mentioned about her present state was...

e. What she assumed about her present state was... 
If an attitude verb has an event(uality) res argument, its semantic type would be $<\mathrm{l},<<\mathrm{i},<\mathrm{s}, \mathrm{t}\rangle>,<\mathrm{e},<\mathrm{s}, \mathrm{t}>>>>$, where 1 is the type of eventualities. This is the Schönfinkeled way of saying that attitude verbs have three arguments: an eventuality, a property of times, and an individual. Suppose now that for those speakers who are comfortable with the present under past cases, the embedded present tense can take the implicit matrix res argument as its antecedent, an option that is bound to be marginal. As a consequence, a zero tense is allowed in the embedded clause, and the semantic selection properties of the verb can be satisfied after insertion of a binder index. To obtain a plausible interpretation, however, the property of times provided by the sentential complement has to be shifted into a property of eventualities. This can be done as follows:

For any $\mathrm{P}$ of type $<\mathrm{i},\left\langle\mathrm{s}, \mathrm{t}>>, * \mathrm{P}=\left[\lambda \mathrm{e}_{\mathrm{l}} \cdot \lambda \mathrm{w}_{\mathrm{s}} \cdot \forall \mathrm{w}_{\mathrm{s}}{ }^{\prime}\left(\mathrm{P}(\operatorname{time}(\mathrm{e}))\left(\mathrm{w}^{\prime}\right)=1\right)\right]\right.$, where time $(e)$ is the running time of $\mathrm{e}$.

According to (38), the property of times [ $\lambda \mathrm{t} . \lambda \mathrm{w}$. Mary is pregnant at $t$ in $w$ ], for example, is mapped into the property of eventualities $Q$ such that for all eventualities e and worlds $w, Q(e)(w)=1$ iff in all possible worlds, the time of e is a time when Mary is pregnant.

Let us go back to (36). The semantics of the verb indicate will establish a suitable connection between its res argument and the property of eventualities provided by the embedded clause. Here are the truth conditions that we should end up with for (36), supposing that the utterance context provides a salient past time interval t:

(39) There is a state $s$ of Mary in $w_{0}$ at $t_{0}$ such that for all ultrasound picture alternatives $<s^{\prime}, w^{\prime}>$ of $s$ in $w_{0}$ at $t, *[\lambda t . \lambda w$.Mary is pregnant at $t$ in $\mathrm{w}]\left(\mathrm{s}^{\prime}\right)\left(\mathrm{w}^{\prime}\right)=1$.

If at $\mathrm{t}$, there was an ultrasound picture of Mary's state on the screen, that state must have existed at $t$, given the way ultrasound imaging works in the actual world. For (36) to be true, then, the time of the state the ultrasound picture is about must overlap the present time as well as $t$.

Abusch proposes that referential tenses are moved out of the scope of attitude verbs because this is what is generally needed to interpret directly referential expressions in those contexts. If we wanted to move each directly referential expression out of attitude verb complements, our syntactic and semantic theories are likely to collapse. The temporal de $r e$ is semantically forced and visible. Counterparts by acquaintance in the sense of Lewis 1983 may be at work for other directly referential expressions in attitude contexts.

\section{Not everything that looks like a tense is a tense}

If tense is pronominal, we need other devices that shift the evaluation time back and forth. Modals may denote future operators. I will suggest in this section, that aspect markers may denote past operators.

There is an interesting contrast between the German and English simple past tense. Imagine you are looking at churches in Italy. There is no previous discourse when the following question comes up: 
a. Who built this Church? Borromini built this church.

b. *Wer baute diese Kirche. Borromini baute diese Kirche. Who built this church? Borromini built this church.

c. Wer hat diese Kirche gebaut? Borromini hat diese Kirche gebaut. Who has this church built? Borromini has this church built.

The English question 40(a) is acceptable out of the blue. If past tense is pronominal, this is surprising. There is no contextually salient past time in this context. The German simple past tense in 40(b) behaves as expected. It is deviant. At best, it sounds like the hypercorrect utterance of a South German speaker. In South German dialects, the simple past is not used, except with a few stative verbs (the old preteropresents). In 40(c) the perfect is used, and the sentence is fine in the assumed situation. I know this is just terminology. But in this case, the terminology seems right. There is quite a bit of evidence that what you see in 40 (c) is a perfect. (41) looks at simple past tenses in embedded sentences.

a. We will answer every letter that we got.

b. Wir werden jeden Brief beantworten, den wir bekamen. We will every letter answer that we received We will answer every letter that we received.

c. Wir werden jeden Brief beantworten, den wir bekommen haben. We will every letteranswer that we gotten have We will answer every letter that we received.

The English sentence 41(a) is fine, even without a contextually salient past interval. The German sentence 41(b) needs a contextually salient past time to be acceptable. If the context doesn't provide such a time, the perfect has to be used, as in 41(c). (42) shows a related difference between German and English:

a. John dreamed about eating a fish that he caught himself. (Underlined Past tense does not have to be anaphoric.)

b. Hans träumte davon, einen Fisch zu essen, den er selber fing. Hans dreamed of it a fish to eat that he himself caught Hans dreamed about eating a fish that he caught himself. (Underlined past tense must be anaphoric.)

c. Hans träumte davon, einen Fisch zu essen, den er selber gefangen Hans dreamed of it a fish to eat that he himself caught hatte.

had.

Hans dreamed about catching a fish that he had caught himself.

The underlined past tense in the English sentence 42(a) can have a backward shifted reading. The corresponding past tense in the German sentence 42 (c) must be anaphoric. To get the backward shifted reading in German, the past perfect has to be used.

The data just reviewed support the idea that the English verbs in the simple past tense form are not just verbs with a pronominal past tense stuck onto it. I want to suggest that what might look like mere past tense morphology may sometimes 
spell out certain tense/aspect combinations. In the syntax, there would be an aspect projection somewhere below the tense projection, and verb+aspect combinations would move to adjoin to tense.

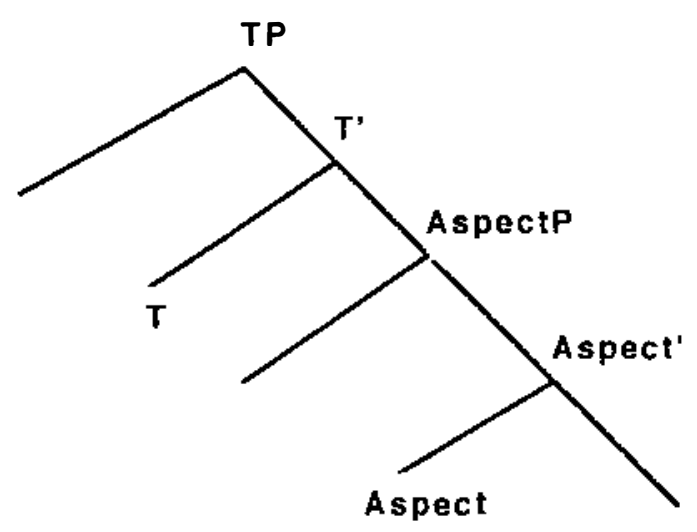

If the sister nodes of Aspect (VPs or maybe VoicePhrases) denote properties of events, then aspect heads should denote operators that map properties of events into properties of times. In this way, they can impose conditions on the relation between event time and reference (topic) time, as informally described in Klein 1994. Here is a proposal for the denotations of three major aspects that is in the spirit of Klein.

Imperfective

$\lambda \mathrm{P}_{<1,<\mathrm{s}, \mathrm{t}>>} \cdot \lambda \mathrm{t}_{\mathrm{i}} \cdot \lambda \mathrm{w}_{\mathrm{s}} \cdot \exists \mathrm{e}_{\mathrm{l}}(\mathrm{t} \subseteq \operatorname{time}(\mathrm{e}) \& \mathrm{P}(\mathrm{e})(\mathrm{w})=1)$ 'reference time included in event time'

Perfective

$\lambda \mathrm{P}_{<\mathrm{l},<\mathrm{s}, \mathrm{t}>>} \cdot \lambda \mathrm{t}_{\mathrm{j}} \cdot \lambda \mathrm{w}_{\mathrm{s}} \cdot \exists \mathrm{e}_{\mathrm{l}}(\operatorname{time}(\mathrm{e}) \subseteq \mathrm{t} \& \mathrm{P}(\mathrm{e})(\mathrm{w})=1)$ 'event time included in reference time'

Perfect

$$
\begin{aligned}
& \lambda \mathrm{P}_{<1,<\mathrm{s}, \mathrm{t}>>} \cdot \lambda \mathrm{t}_{\mathrm{i}} \cdot \lambda \mathrm{w}_{\mathrm{s}} \cdot \exists \mathrm{e}_{1}(\operatorname{time}(\mathrm{e})<\mathrm{t} \& \mathrm{P}(\mathrm{e})(\mathrm{w})=1) \\
& \text { 'event over by reference time' }
\end{aligned}
$$

For our present discussion, the perfect is the most relevant aspect. What I have called 'Perfect' is only one particular type of perfect, of course, and should not be confused with, say, the perfect formed with the auxiliary have in English. The simple Perfect here simply marks that the event is over by the reference time. Present tense combined with perfect aspect contributes the information that the event described is over by the utterance time. In an out of the blue utterance past events have to be described by relying on the utterance time as reference time. Since we can't point or look at times, in the absence of previous discourse, the utterance time is the only possible reference for an indexical tense. Since the simple past in English can be used in out of the blue utterances describing past events, it must be a way of spelling out perfect aspect and present tense together.

The picture about tense/aspect combinations that I just sketched yields a plausible typology of what has been called 'tenses' in English, German, and French. I conclude this presentation with some tables for further thought. 
English tense and aspect interactions

\begin{tabular}{|c|c|c|}
\hline & Present Reference Time & Past Reference Time \\
\hline Imperfective & Present Progressive & Past Progressive \\
\hline Perfective & Reporter's Present & Simple Past \\
\hline Perfect & Simple Past & $\begin{array}{c}\text { Simple Past or Past } \\
\text { Perfect }\end{array}$ \\
\hline
\end{tabular}

Standard German

\begin{tabular}{|c|c|c|}
\hline & Present Reference Time & Past Reference Time \\
\hline Imperfective & Present & Simple Past \\
\hline Perfective & Present & Simple Past \\
\hline Perfect & Present Perfect & Past Perfect \\
\hline
\end{tabular}

South German

\begin{tabular}{|c|c|c|}
\hline & Present Reference Time & Past Reference Time \\
\hline Imperfective & Present & Present Perfect \\
\hline Perfective & Present & Present Perfect \\
\hline Perfect & Present Perfect & Double Perfect \\
\hline
\end{tabular}

French

\begin{tabular}{||c|c|c|}
\hline & Present Reference Time & Past Reference Time \\
\hline Imperfective & Présent & Imparf ait \\
\hline Perfective & Présent & Passé Simple \\
\hline Perfect & Passé Composé & Passé Antérieur \\
\hline
\end{tabular}




\section{Endnotes}

1. Try other indexical pronouns in Heim's example. They behave like $I$.

2. Rather than having fully spelled out pronouns, we could have sets of features, of course. I am disregarding traces and reflexive pronouns.

3. The NPs (or DPs) headed by indexical pronouns can have indices, though. These indices will be interpreted as binder indices ( $\boldsymbol{\lambda}$-operators), as proposed in Heim and Kratzer 1998.

4. I am grateful to Peggy Speas for making Cardinaletti \& Starke's work available to me. There is a substantial recent body of work on the distribution of unpronounced pronouns within optimality theory (see e.g. Speas 1997, 1998, and the references cited there). See also Richards 1997 for important observations concerning the typology of anaphora. I feel that these works will all become relevant once the spell-out of zero pronouns is seriously addressed.

5. Thanks to Ana Arregui for the data.

6. The term 'equidistant' is from Chomsky 1995.

7. Thanks to Philippe Schlenker for providing this kind of example. His actual example was: Only I married a woman that Mary thought I shouldn't have married.

8. The basic semantic types are: $s$ for worlds, $i$ for times, e for individuals, and $\mathrm{t}$ for truth-values.

9. To be precise, I would have to talk about a contextually determined time including $\mathrm{t}_{0}$.

10. There is another deviant reading where John locates himself at a time with the property $\left[\lambda t . \lambda w\right.$. there is a time $t^{\prime}$ before $t$ such that $t^{\prime}$ is part of yesterday $\&$ you are sick at $t^{\prime}$ in $\left.w\right]$. See section 7 below. 


\section{References}

Abusch, Dorit: "Sequence of Tense and Temporal De Re". Linguistics and Philosophy 20(1), 1997, 1-50.

Borer, Hagit: "Anaphoric AGR". In O.Jaeggli and K.J. Safir (eds.): The Null Subject Parameter. Dordrecht (Kluwer Academic Publishers), 1989, 69109.

Baker, Mark: Incorporation. Chicago (Chicago University Press), 1988.

Cardinaletti, Anna \& Starke, Michal: "Deficient Pronouns - A View from Germanic". GenGenP 3(1), 1995.

Cardinaletti, Anna \& Starke, Michal: "The Typology of Structural Deficiency. On the Three Grammatical Classes." To appear in van Riemsdijk (ed.): Clitics in the Languages of Europe. Vol 8 of Language Typology. Mouton, Berlin (to appear).

Chomsky, Noam: The Minimalist Program. Cambridge/Mass., 1995.

Hashemipour, Peggy: "Finite Control in Modern Persian". In H. Borer (ed.): Proceedings of WCCFL 1988, 115-128.

Heim, Irene: "Comments on Abusch's Theory of Tense." In H. Kamp (ed.): Ellipsis, Tense and Questions." Dyana 2 Deliverable, 1994, 143-170.

Hendrick, Randall: “Construing Relative Pronouns." Linguistic Analysis 9, 1983, 205-224.

Hendrick, Randall: Anaphora in Celtic and Universal Grammar. Dordrecht (Kluwer Academic Publishers), 1988.

Klein, Wolf gang: Time in Language. London (Routledge), 1994.

Kratzer, Angelika: "Scope or Pseudoscope? Are there Wide Scope Indefinites?" In: Susan Rothstein (ed.): Events in Grammar. Dordrecht (Kluwer) 1998.

Lewis, David: "Individuation by Acquaintance and by Stipulation." Philosophical Review 92, 1983, 3-32.

Ogihara, Toshiyuki: "Double-Access Sentences and Reference to States". Language Semantics 3(2), 1995, 177-210.

Partee, Barbara: "Some Structural Analogies Between Tenses and Pronouns in English". Journal of Philosophy 70, 1973, 601-609.

Reinhart, Tanya and Eric Reuland: "Reflexivity". Linguistic Inquiry 24(4), 1993, 657-720.

Saxon, Leslie: "Control and Agreement in Dogrib". In: Proceedings of the First Eastern States Conference on Linguistics, 1984,128-139.

Speas Margaret: "Optimality Theory and Syntax: Null Pronouns and Control". In: D. Archangeli and T. Langendoen (eds.): Optimality Theory. Oxf ord (Blackwell Publishers), 1997.

Speas, Margaret: "Constraints on Null Pronouns", ms. UMASS Amherst.

v. Stechow, Arnim: "Structured Propositions". Report of Sonderforschungsbereich 99, University of Konstanz, 1982.

v. Stechow, Arnim: "Tense in Intensional Contexts: Two Accounts of Abusch's Theory of Tense." In: F. Hamm and A. v. Stechow (eds.): The Blaubeuren Papers: Proceedings of the Workshop on Recent Developments in the Theory of Natural Language Semantics, 1994, 379-433.

v. Stechow, Arnim: "On the Proper Treatment of Tense". In M. Simons and T. Galloway (eds.): Proceedings of SALT V, 1995.

Stowell, Timothy: "The Phrase Structure of Tense". In: Johan Roryck and Laurie Zaring (eds.): Phrase Structure and the Lexicon, 1996, 277-291.

Yang, Dong-Whee: "On the Integrity of Control Theory". In: S. Berman, J.-W. Choe, and J. McDonough (eds.): Proceedings of NELS 15, 1985, 389408. 